American Journal of Pharmaceutical Education 2019; 83 (8) Article 7212.

\title{
BRIEF
}

\section{How Pharmacist Preceptors Foster Students' Therapeutic Reasoning Using the One-Minute Preceptor Method}

\author{
Kayley Lyons, PharmD, ${ }^{\text {a,b }}$ Jacqueline E. McLaughlin, PhD, ${ }^{a}$ Michael D. Wolcott, PharmD, a,b \\ Rebecca Grandy, PharmD, ${ }^{\text {c,d }}$ Charlene R. Williams, PharmD ${ }^{\mathrm{d}}$ \\ ${ }^{a}$ University of North Carolina at Chapel Hill, Eshelman School of Pharmacy, Chapel Hill, North Carolina \\ ${ }^{\mathrm{b}}$ University of North Carolina at Chapel Hill, School of Education, Chapel Hill, North Carolina \\ ${ }^{\mathrm{c}}$ Mountain Area Health Education Center, Asheville, North Carolina \\ ${ }^{\mathrm{d}}$ University of North Carolina at Asheville, Eshelman School of Pharmacy, Asheville, North Carolina \\ Submitted June 14, 2018; accepted March 24, 2019; published October 2019.
}

\begin{abstract}
Objective. To compare whether preceptors trained in the One-Minute Preceptor (OMP) method versus preceptors not trained in the OMP method use OMP methods, and whether their students demonstrate more frequent expression of therapeutic reasoning processes during case presentations.

Methods. A pilot quasi-experimental study was conducted. In 2015, four preceptors attended an OMP training session. The OMP preceptors and three preceptors not trained in OMP were asked to collect audio recordings of their students presenting patient cases. The audio recordings were coded for preceptors' use of OMP methods and students' expression of therapeutic reasoning processes.

Results. In total, we collected 42 audio recordings from 27 students presenting a patient case to one of seven preceptors. Preceptors trained in OMP more frequently asked students to commit to a therapeutic assessment and plan, probed for their supporting reasoning, and reinforced what was done well. However, non-OMP preceptors' students more frequently articulated assessments and treatment plans in their case presentations. The non-OMP students also more frequently initiated discussion about the reasoning behind their assessments and plans without prompting from their preceptor.

Conclusion. Implementing OMP workshops for preceptors to elicit students' therapeutic reasoning processes requires further consideration. Future research is needed on pragmatic and effective precepting methods.
\end{abstract}

Keywords: preceptor development, therapeutic reasoning, clinical reasoning, critical thinking, one-minute preceptor

\section{INTRODUCTION}

As medical treatments become more and more complex, schools and colleges of pharmacy must foster pharmacy students' therapeutic decision-making and reasoning. ${ }^{1}$ Researchers have defined therapeutic reasoning and decisionmaking as planning, implementing, and evaluating the outcomes of therapy. ${ }^{2}$ Therapeutic reasoning, specifically, is an optional process that occurs during therapeutic decision-making when several therapeutic options exist. ${ }^{3}$ Health professions schools and colleges often rely on preceptors (ie, practicing pharmacists) to promote students' therapeutic decision-making and reasoning. However, there is a dearth of research on how preceptors may opti-

Corresponding Author: Charlene Williams, University of North Carolina at Asheville, UNC Eshelman School of Pharmacy, One University Heights CB\# 2125, Asheville, NC 28804. Tel: 828-250-3906.E-mail:charlene_williams@unc.edu mally promote students' therapeutic decision-making and reasoning.

In the practice setting, preceptors formally and informally teach students to reason through real-life patient cases by having students present patient cases and then providing them with feedback. During a case presentation, preceptors have a dual goal of supporting students to internalize reasoning processes and ensure appropriate patient care. ${ }^{4}$ Said differently, preceptors must evaluate both the patients' therapy and the students' clinical knowledge and reasoning. Therefore, one goal of research on precepting methods should be to create and test whether preceptor methods are effective and feasible.

The One-Minute Preceptor (OMP) method has proven to be effective and efficient medical education. ${ }^{5}$ Neher and colleagues first described the OMP in 1992 as an alternative to a traditional model of precepting. ${ }^{5}$ In the traditional model of precepting, preceptors concentrated on assessing 


\section{American Journal of Pharmaceutical Education 2019; 83 (8) Article 7212.}

students' patient case presentations to focus solely on the care for the patient, which may not elicit the learner's thinking process. ${ }^{6}$ In the OMP method, preceptors concentrate on patient care and student learning by prompting students to explain their thinking process and then providing needed learning support. Preceptors ask students open-ended questions using five "microskills" to elicit learner's reasoning processes: get a commitment, probe for supporting evidence, teach general rules, reinforce what was done right, and correct identified mistakes. ${ }^{7}$ In OMP studies, medical education researchers have found evidence indicating positive preceptor perceptions, ${ }^{8-10}$ positive to neutral learner perceptions, ${ }^{8,11,12}$ improved ability for preceptors to diagnose the patient, ${ }^{10}$ and increased OMP-related teaching behaviors as rated by learners. ${ }^{11}$ However, these studies were conducted in simulated (ie, non-practice) settings, ${ }^{6,10}$ utilized self-report data, ${ }^{8-12}$ and only focused on how medical learners reasoned through and made decisions about patient diagnoses. What remains unknown is whether the OMP method can be applied in pharmacy education and whether training pharmacy preceptors in the OMP method leads to observable differences in real-world precepting practices.

We chose to first pilot the OMP with a small number of preceptors because we wanted to ensure the method had sufficient evidence for feasibility and effectiveness in the pharmacy context before scaling the study to a larger number of preceptors. The purpose of this study was to investigate whether pharmacist preceptors trained in the OMP method applied the principles of this method and whether their students initiated more frequent therapeutic decision-making and reasoning processes during oral patient care presentations. Our hypothesis was that preceptors training in the OMP method would more frequently apply it during student case presentations. In turn, we hypothesized that their students would express more therapeutic decision-making and reasoning processes than students in a control group.

\section{METHODS}

The Institutional Review Board at the University of North Carolina at Chapel Hill determined this study to be exempt from a full committee review. Participants included advanced pharmacy practice experience (APPE) pharmacist preceptors of a school of pharmacy and students enrolled in the fourth-year of a professional Doctor of Pharmacy (PharmD) program when APPEs occur. One of the co-investigators recruited seven pharmacy preceptors for this study through listserv emails, directed emails, and follow-up, in person meetings. We purposively sampled pharmacy preceptors who were Certified Pharmacy Practitioners (CPP) and precepted the school's APPE students. The CPPs were clinic-based pharmacists who had prescribing rights and provided comprehensive medication management ${ }^{13}$ under the supervision of a physician in the state of North Carolina. We selected CPP pharmacists because their clinic practice sites, compared to other practice sites, provided ample opportunity for students to perform patient case presentations. Under tailored guidance from their preceptor, students provided comprehensive medication management to ensure patients' medications were appropriate, safe, and effective. The students visited with patients, reviewed assessments of the patients' clinical status (eg, blood pressure), and developed patient-centered care plans. Of the CPPs who precepted the school's APPE students, we conveniently sampled from specific geographical locations to maintain communication with the study preceptors during the length of the study. No financial incentives were provided for study participation.

We conducted a quasi-experimental pilot study with four preceptors in the intervention (OMP) group and three preceptors in the control group. The intervention group and control group were selected based on convenience, ie, the intervention group CPPs were all recruited from one region of North Carolina so that they could all attend the same OMP workshop. The control group was recruited from the rest of the CPPs in the state who were also practicing in ambulatory environments. Preceptors that responded to the recruitment request were all located in one region of North Carolina that was distinct from the location of the intervention group. The preceptors in both groups had an average of 7.1 years (range, 2-19 years) of experience precepting students. Although all of the preceptors provided comprehensive medication management in clinics, they specialized in family medicine $(n=5)$, internal medicine $(n=1)$, or oncology $(n=1)$.

In 2015, the OMP preceptors attended a two-hour long OMP workshop delivered by one of the co-investigators. The workshop was adapted from Kertis, ${ }^{14}$ but with the addition of video examples. In the workshop, the coinvestigator first outlined each of the five OMP steps, providing examples and nonexamples, and then provided a brief review of the OMP literature. Then the OMP preceptors watched a YouTube (San Bruno, CA) example of a physician preceptor using the OMP with a medical student. ${ }^{15}$ Next, the preceptors role played the OMP method, using two case scenarios. After practicing with the scenarios, preceptors reflected on use of the OMP method and had the opportunity to ask questions. The co-investigator provided the OMP preceptors with a one-page handout to take with them that included a review of each OMP step and sample questions for preceptors to ask students under each OMP step. 


\section{American Journal of Pharmaceutical Education 2019; 83 (8) Article 7212.}

Data collection included audio recordings of student oral case presentations to their preceptor. The audio recordings were of students presenting a patient case to their preceptor during the last three days of their clerkship. We decided to collect case presentations during the last three days of clerkships to allow sufficient time for students to be familiar with each preceptors' case presentation method. For two years (2015-2016), preceptors asked their assigned students if they could audio record two of their case presentations, assuring the student that no patient, preceptor, or student identifiers would be included. It took two years to capture a sufficient number of cases in both the control and OMP groups because of the low number of students scheduled to complete their APPEs with the preceptors selected for the study. All of the pharmacy students whose presentations were included in the study were in their fourth year of the PharmD program, and none were precepted by both a control and intervention group preceptor. The majority of cases involved a patient with multiple chronic disease states who was taking several medications. However, some patient cases involved a patient with only one disease state. Preceptors in the intervention group were reminded by email to continue using OMP methods in year two of data collection.

We asked preceptors in the control group to conduct their usual and customary case presentation review with their students. We did not ask those preceptors to use a standardized case presentation format because it was important that the OMP method fit within real-world teaching practice. The OMP preceptor group was aware that we were studying the effectiveness of the OMP method, and the control group was aware that they were in a control group as part of a study evaluating the use of a precepting method. To reduce the risk of control group contamination, ${ }^{16}$ the control group was not given the name of the exact precepting method used by the intervention group. At the beginning of the data collection, preceptors provided us with a description of their student case presentation procedures so we could understand the context during data analysis. To limit treatment-control contamination, we ensured that the control group preceptors' procedures did not match the OMP method. Typically, the study preceptors provided students with time to work-up the patient case before meeting together and then asked the students to present the patient case either before or after the patient's clinic visit. During the case presentation, students were generally asked to provide pertinent background information (eg, patient's age), their assessment (eg, "the patient's diabetes is uncontrolled"), and their treatment plan (eg, to increase the patient's insulin dose by 10 units). Preceptors either asked questions throughout the students' case presentation or after the students' presentation. Then after the patient visit, the preceptor followed up with the student with any changes to the assessment or plan. The audio recordings captured the case presentations before or after the patient visit.

The audio recordings were analyzed using directed content analysis procedures. ${ }^{17}$ The audio recordings were sent to Rev.com (Rev, San Fransisco, CA) for verbatim transcription. Each transcription was then coded by two of three coders. Two of the coders were residency-trained pharmacists and one was an education researcher. The three coders independently coded the transcripts for the use of OMP methods and student expression of therapeutic reasoning processes. The codes were first developed by available literature and then fine-tuned through iterations and conversations between coders. The coders were blinded to OMP method versus control group. The coding procedures included a calibration phase and then three phases in which sections (ie, one-third of each phase) of the data were coded. After each phase, the codes were fine-tuned and intercoder reliability was calculated using simple agreement and Cohen's kappa,${ }^{18}$ which includes an adjustment for chance to total observed agreement. Calculating rater agreement provided an estimate of intercoder reliability, ie, whether the coders thought the same constructs applied to the same sections of text. ${ }^{19}$ The percent agreement signified the proportion of time the coders agreed (yes or no) that each code occurred in each case presentation.

To measure the use of OMP methods by the preceptor, the coders coded for each time evidence of using a specific step of the OMP method was found in the transcript (Table 1). ${ }^{5}$ However, two of the OMP steps were partitioned into two separate codes. First, we divided the "probe for supporting evidence" method into whether the preceptor was using a question to assess students' knowledge recall of the patient case or topic area ("probe for supporting evidence - knowledge recall") or students reasoning for the assessment or plan ("probe for supporting evidence - reasoning"). We divided out reasoning from knowledge as we believed this was a crucial and deeplearning outcome of the OMP method. ${ }^{6}$ Second, we divided "correct errors" into whether the preceptor provided constructive feedback on the student's thinking, answers, or case presentation ("correct errors - feedback") or provided specific recommendations for how the learner could improve their thinking or case presentation ("correct errors - recommendations"). We made this decision because of the general teaching literature advocating for the benefits of teachers explicitly instructing their students on learning strategies. ${ }^{20,21}$

To code for students' expression of therapeutic decision-making and reasoning, the researchers created the 


\section{American Journal of Pharmaceutical Education 2019; 83 (8) Article 7212.}

Table 1. Codes for the One-Minute Preceptor (OMP) ${ }^{6}$ Model Used in a Study to Determine Best Practices for Fostering Pharmacy Students' Therapeutic Reasoning Skills

\begin{tabular}{|c|c|c|}
\hline Variable Codes & Adapted From & Operational Definition and Example \\
\hline Get a commitment & OMP Method 1 & $\begin{array}{l}\text { The preceptor prompts the student to discuss their own assessment or } \\
\text { treatment plan. } \\
\text { Examples: "What do you want to do for the patient's diabetes?," "Is } \\
\text { the patient's diabetes controlled?" }\end{array}$ \\
\hline $\begin{array}{l}\text { Probe for supporting } \\
\text { evidence - reasoning }\end{array}$ & OMP Method 2 & $\begin{array}{l}\text { The preceptor probes to evaluate the student's reasoning underlying } \\
\text { their assessment or plan. Includes prompts for 1) explanation of } \\
\text { their supporting evidence, 2) presenting more than one option, or } \\
\text { 3) making comparisons between two possibilities for the } \\
\text { assessment or treatment plan. } \\
\text { Example: "Why did you choose a long acting insulin?" }\end{array}$ \\
\hline $\begin{array}{l}\text { Probe for supporting } \\
\text { evidence }- \text { knowledge recall }\end{array}$ & OMP Method 2 & $\begin{array}{l}\text { The preceptor probes to evaluate the student's knowledge or concept } \\
\text { understanding. Includes general questioning about medications, } \\
\text { disease states, and other medical related concepts and questioning } \\
\text { on the facts of the patient case. } \\
\text { Examples: "What are the causes of hypertension?," "What was the } \\
\text { patient's blood pressure?" }\end{array}$ \\
\hline Teach general rules & OMP Method 3 & $\begin{array}{l}\text { The preceptor explains some common "take home points." } \\
\text { Example: "Metronidazole causes nausea." }\end{array}$ \\
\hline Reinforce what was done well & OMP Method 4 & $\begin{array}{l}\text { The preceptor provides specific positive feedback. } \\
\text { Example: "That is an excellent summary. It shows you took a detailed } \\
\text { medication history." }\end{array}$ \\
\hline Correct errors & OMP Method 5 & $\begin{array}{l}\text { The preceptor provides constructive feedback on the student's } \\
\text { thinking, answers, or case presentation. } \\
\text { Example: "I would not choose pioglitazone because he has a history } \\
\text { of heart failure." }\end{array}$ \\
\hline Correct errors - recommendations & OMP Method 5 & $\begin{array}{l}\text { The preceptor provides recommendations for improvement. } \\
\text { Example: "Next time I want you to present from highest priority } \\
\text { problem to lowest." }\end{array}$ \\
\hline
\end{tabular}

Abbreviations: $\mathrm{OMP}=$ One-Minute Preceptor

codes from previous research and based on their own experience with clinical precepting (Table 2). The Thinking Behavior Scale ${ }^{22}$ and the SNAPPS technique ${ }^{23}$ are focused on diagnostic reasoning. These scales were adapted to therapeutic decision-making and reasoning for this study based on the authors' clinical experience. We hypothesized that over the course of the clerkship, students would internalize preceptors' prompts for committing to an assessment and plan and explaining supporting evidence. Therefore, we believe an important learning outcome was whether students self-initiated discussions of therapeutic assessments, therapeutic plans, and supporting evidence. We specifically differentiated each therapeutic decision-making and reasoning variable as to whether it was prompted by the preceptor or self-initiated by the student.

Because intercoder reliability was substantial after each coding phase and the coders were blinded to which case presentations were control group and which were the OMP group, we decided it was not necessary to meet and resolve coder disagreements for each code. Instead, we calculated the average number of codes between the two coders for each case presentation. For example, if one coder noted that the case presentation had five "get a commitment" codes and another coder noted seven, then the frequency was determined to be six. To test betweengroup means of frequency, we used a two-sample $t$ test with unequal variances at the .05 level of significance. In addition to the number of occurrences, or frequency, of each code, we tested for the simple occurrence (yes or no) of each code. As the coders did not meet to resolve discrepancies between their codes, an occurrence was determined if one or both coders noted that the code occurred. To test for between-group differences in the occurrence of codes, we used the chi square test at the .05 level of significance.

\section{RESULTS}

We collected a total of 42 audio observations from 27 students presenting a patient case to one of seven 


\section{American Journal of Pharmaceutical Education 2019; 83 (8) Article 7212.}

Table 2. Codes for Pharmacy Students' Expression of Therapeutic Decision Making and Reasoning in a Study to Determine Best Practices for Fostering Pharmacy Students' Therapeutic Reasoning Skills

\begin{tabular}{|c|c|c|}
\hline Variable & Adapted From & Operational Definition \\
\hline $\begin{array}{l}\text { Student self-initiates the articulation } \\
\text { of an assessment or treatment plan }\end{array}$ & $\begin{array}{l}\text { OMP Method 1, The } \\
\text { Thinking Behavior } \\
\text { Scale }^{20}\end{array}$ & $\begin{array}{l}\text { Student self-initiates discussion of their own assessment or } \\
\text { treatment plan. } \\
\text { Examples: "I think we should increase lisinopril," "The } \\
\text { patient's diabetes is uncontrolled." }\end{array}$ \\
\hline $\begin{array}{l}\text { Student articulates an assessment or } \\
\text { treatment plan }\end{array}$ & $\begin{array}{l}\text { OMP Method 1, The } \\
\text { Thinking Behavior } \\
\text { Scale }^{20}\end{array}$ & $\begin{array}{l}\text { Student either self-initiates or is prompted to discuss their own } \\
\text { assessment or treatment plan. } \\
\text { Example of prompting: "What do you want to do for the } \\
\text { patient's diabetes?" }\end{array}$ \\
\hline $\begin{array}{l}\text { Student self-initiates the articulation } \\
\text { of reasoning for the assessment or } \\
\text { plan }\end{array}$ & $\begin{array}{l}\text { OMP Method 2, SNAPPS } \\
\text { technique }^{21}\end{array}$ & $\begin{array}{l}\text { For the assessment or treatment plan, the student initiates an 1) } \\
\text { explanation of their supporting evidence, 2) presents more than } \\
\text { one option, or 3) makes comparisons between two possibilities. } \\
\text { Examples: "Since his A1C is } 7 \text {, I think..." "We could use an } \\
\text { ACEI or an ARB." }\end{array}$ \\
\hline Student information seeking & $\begin{array}{l}\text { The Thinking Behavior } \\
\text { Scale }^{20} \text { and SNAPPS } \\
\text { technique }^{21}\end{array}$ & $\begin{array}{l}\text { Student-initiated questions about uncertainties and areas } \\
\text { needing clarification after patient summary. } \\
\text { Examples: "I need to ask the patient about their medication } \\
\text { adherence," "How is insulin dosing determined?" }\end{array}$ \\
\hline
\end{tabular}

Abbreviations: $\mathrm{OMP}=$ One-Minute Preceptor

preceptors. Five audio recordings across both groups were not analyzed because of poor audio quality. Three of the inaudible recordings were from preceptors in the control group, while two were from preceptors in the study group. For interrater reliability of the coding, the simple agreement was $81.3 \%$ and the kappa was 0.63 , which represents substantial agreement. ${ }^{24}$ There were no significant differences in the average length of case presentation between the control group $(\mathrm{M}=510$ seconds, $\mathrm{SD}=70$ seconds $)$ and OMP group ( $\mathrm{M}=444$ seconds, $\mathrm{SD}=52$ seconds, $p=.45)$.

As noted in Table 3, the OMP preceptors more frequently asked students to commit to a therapeutic assessment and plan, probed for their supporting reasoning, and reinforced what was done well. The OMP and control group had nonsignificant differences in the frequency of the remaining OMP methods (eg, teaching general rules). Also noted in Table 3, the OMP preceptors' case presentations more often contained the presence of probing for supporting reasoning and reinforcing what was done well. For the occurrence of the remaining OMP methods, the OMP and control group had nonsignificant differences.

As noted in Table 4, compared to the control students, the OMP students less frequently self-initiated the articulation of an assessment or treatment plan and the reasoning behind their assessment or treatment plan. Also, the OMP students less frequently articulated assessments and treatment plans in their case presentations regardless of whether they were self-initiated or prompted by their preceptor. The OMP and control group had nonsignificant differences in their mean frequency for the remaining therapeutic decision-making and reasoning factors. The OMP and control group students had nonsignificant differences in the occurrence of codes for all factors.

\section{DISCUSSION}

In studying preceptors who attended and did not attend a two-hour OMP workshop, we observed several notable findings. First, pharmacist preceptors who attended the workshop more frequently used OMP methods, including getting a commitment, probing for student reasoning, and reinforcing what was done well. However, these preceptors did not differ from the control group in probing for knowledge recall, teaching general rules, or correcting student errors. Second, pharmacy students of OMP preceptors expressed less therapeutic decision-making and reasoning processes in their case presentations than students of preceptors in the control group. 
American Journal of Pharmaceutical Education 2019; 83 (8) Article 7212.

Table 3. Preceptors' Use of the One-Minute Preceptor Method in a Study to Determine Best Practices for Fostering Pharmacy Students' Therapeutic Reasoning Skills ${ }^{\mathrm{a}}$

\begin{tabular}{|c|c|c|c|c|c|c|}
\hline & \multicolumn{3}{|c|}{ Frequency of Code in Each Case Presentation } & \multicolumn{3}{|c|}{ Presence of Code $^{\mathrm{a}}$} \\
\hline & $\begin{array}{c}\text { OMP Cases } \\
(\mathrm{N}=25), \text { Mean } \\
\text { (SD) }\end{array}$ & $\begin{array}{c}\text { Control Cases } \\
(\mathrm{N}=17) \text {, Mean } \\
\text { (SD) }\end{array}$ & $\begin{array}{c}\text { t Test } \\
(p \text { Value })\end{array}$ & $\begin{array}{l}\text { OMP Cases } \\
(\mathrm{N}=\mathbf{2 5}), \mathrm{n}(\%)\end{array}$ & $\begin{array}{l}\text { Control Cases } \\
(\mathrm{N}=17), \mathrm{n}(\%)\end{array}$ & $\begin{array}{c}\text { Chi square } \\
\text { (p Value) }\end{array}$ \\
\hline Get a commitment & $4.0(2.7)$ & $2.4(2.0)$ & $2.09(.03)^{\mathrm{b}}$ & $24(96)$ & $14(82)$ & $2.18(.14)$ \\
\hline $\begin{array}{l}\text { Probe for supporting } \\
\text { evidence - knowledge } \\
\text { recall }\end{array}$ & $3.6(4.1)$ & $3.0(2.3)$ & $.62(.54)$ & $23(92)$ & $13(76)$ & $1.99(.16)$ \\
\hline $\begin{array}{l}\text { Probe for supporting } \\
\text { evidence - reasoning }\end{array}$ & $1.5(1.0)$ & $0.8(1.0)$ & $2.18(.03)^{\mathrm{b}}$ & $22(88)$ & $10(59)$ & $4.75(.03)^{\mathrm{b}}$ \\
\hline Teach general rules & $1.6(1.5)$ & $1.5(1.7)$ & $.06(.95)$ & $20(80)$ & $14(82)$ & $.04(.85)$ \\
\hline $\begin{array}{l}\text { Reinforce what was done } \\
\text { well }\end{array}$ & $1.7(0.9)$ & $0.6(0.7)$ & $4.56(<.001)^{\mathrm{b}}$ & $23(92)$ & $8(47)$ & $10.57(.001)^{\mathrm{b}}$ \\
\hline Correct errors - feedback & $0.8(1.3)$ & $1.7(2.5)$ & $-1.40(.17)$ & $13(52)$ & $10(59)$ & $.19(.66)$ \\
\hline $\begin{array}{l}\text { Correct errors - } \\
\text { recommendations }\end{array}$ & $0.4(0.9)$ & $0.7(1.4)$ & $-.74(.46)$ & $6(24)$ & $6(35)$ & $.63(.43)$ \\
\hline
\end{tabular}

Abbreviations: OMP $=$ One-Minute Preceptor

${ }^{a}$ Presence indicates the method was coded at least once by one or more coders in the audio transcript

${ }^{\mathrm{b}} p<.05$

We found it encouraging that the preceptors who attended an OMP workshop prompted their students to commit to assessments and plans, explain their reasoning, and reinforce what the students did well. This is the first study in any discipline, to our knowledge, that directly observed preceptors in real-world settings following OMP training. Therefore, we cannot directly compare our results to other studies as they were conducted in simulated (ie, non-practice) settings ${ }^{10,13}$ and used self-report data. ${ }^{8-12}$ Previous studies used preceptor and learner ratings of preceptor behavior, which have found mixed results. In Furney and colleagues' study of 57 medical preceptors receiving instruction on the OMP, preceptors rated themselves as having improvements in all five OMP methods and their students rated the

Table 4. Pharmacy Students' Expression of Therapeutic Decision Making and Reasoning Factors in a Study to Determine Best Practices for Fostering Pharmacy Students' Therapeutic Reasoning Skills ${ }^{\mathrm{a}}$

\begin{tabular}{|c|c|c|c|c|c|c|}
\hline & \multicolumn{3}{|c|}{$\begin{array}{c}\text { Frequency of Code in Each Case } \\
\text { Presentation }\end{array}$} & \multicolumn{3}{|c|}{ Presence of Code ${ }^{a}$} \\
\hline & $\begin{array}{c}\text { OMP } \\
\text { Cases } \\
(\mathrm{N}=\mathbf{2 5}), \\
\text { Mean (SD) } \\
\end{array}$ & $\begin{array}{c}\text { Control Cases } \\
\text { (N=17), Mean } \\
\text { (SD) }\end{array}$ & $\begin{array}{c}t \text { Test } \\
(p \text { Value })\end{array}$ & $\begin{array}{c}\text { OMP } \\
\text { Cases } \\
(\mathbf{N}=\mathbf{2 5}), \mathbf{n} \\
(\%)\end{array}$ & $\begin{array}{l}\text { Control Cases } \\
(\mathrm{N}=17), \mathrm{n}(\%) \\
\end{array}$ & $\begin{array}{c}\text { Chi } \\
\text { Square } \\
(p \text { Value }) \\
\end{array}$ \\
\hline $\begin{array}{l}\text { Student self-initiates the articulation of } \\
\text { an assessment or treatment plan }\end{array}$ & $3.0(2.1)$ & $8.0(5.2)$ & $-3.81(.001)^{\mathrm{b}}$ & $24(96)$ & $17(100)$ & $0.70(.40)$ \\
\hline $\begin{array}{l}\text { Student either self-initiates or is } \\
\text { prompted to articulate an assessment } \\
\text { or treatment plan }\end{array}$ & $6.9(3.3)$ & $10.5(5.5)$ & $-2.38(.03)^{\mathrm{b}}$ & $25(100)$ & $17(100)$ & Null \\
\hline $\begin{array}{l}\text { Student self-initiates the } \\
\text { articulation of reasoning for the } \\
\text { assessment or plan }\end{array}$ & $2.4(2.0)$ & $4.3(2.9)$ & $-2.28(.03)^{\mathrm{b}}$ & $21(84)$ & $17(100)$ & $3.01(.08)$ \\
\hline $\begin{array}{l}\text { Student either self-initiates or is } \\
\text { prompted to articulate the reasoning } \\
\text { for the assessment or plan }\end{array}$ & $3.9(2.2)$ & $5.1(3.4)$ & $-1.23(.23)$ & $24(96)$ & $17(100)$ & $0.70(.40)$ \\
\hline Student information seeking & $0.7(0.9)$ & $1.5(2.0)$ & $-1.52(.14)$ & $14(56)$ & $8(47)$ & $0.32(.57)$ \\
\hline
\end{tabular}




\section{American Journal of Pharmaceutical Education 2019; 83 (8) Article 7212.}

preceptors as having improvements in all methods except teaching general rules. ${ }^{11}$ In contrast, Eckstrom and colleagues' study of 68 physician preceptors found no significant differences in ratings of teaching behavior. ${ }^{9}$

We also found that no statistical differences between the groups' use of probing for knowledge recall, teaching general rules, providing corrective feedback, or providing recommendations for improvement. From our experience, we believe probing for knowledge recall and teaching general rules were already a usual and customary standard for preceptors. However, the lack in both groups of correcting student errors and providing students with recommendations was noteworthy. One possible reason for this result is that preceptors may believe they are providing indirect feedback to students through sophisticated questioning. Another explanation may be that preceptors do not value, are not comfortable with, or do not know how to provide students with corrective feedback and recommendations. Alternatively, the students may have had less errors to correct or provide recommendations on at the end of the rotation. Future studies are needed to explore the range of possibilities from our results.

Of note, we found control students expressed more therapeutic assessments, plans, and reasoning than the OMP students. This was unexpected as a previous evaluation of an OMP workshop found that medical students' rated OMP trained preceptors as greater involving them in patient case decision-making, thereby prompting the students to express more assessments and plans. ${ }^{11}$ One possible explanation of our results is that the use of OMP methods encourages preceptors to take sole responsibility for the direction of the case presentation, thereby limiting opportunities for students to initiate discussion of their assessments, plans, and reasoning. If confirmed in future studies, this would be notable as an aim of these interactions is for the pharmacy students to move towards being independent practitioners. ${ }^{25}$ However, these conclusions cannot be said with confidence as this study had a limited sample size and did not include randomization. Thus, the effects could be the result of outside factors. Also, the two studies differed in the measurement of preceptors' behavior (ie, direct observation versus recall surveys) and population (ie, pharmacy versus medical students). Also, we measured the quantity for reasoning expression rather than the context-specific quality or depth of reasoning. Therefore, another explanation may be that although the OMP students had less frequent expression of therapeutic reasoning processes, when they did express reasoning, it was perhaps of higher quality. Regardless, there is a need and opportunity to pair preceptor development with student development in structuring case presentations to foster therapeutic reasoning expression. ${ }^{26}$
Because there was no available evidence for the feasibility and effectiveness of using the OMP method in pharmacy precepting, we conducted a pilot study with a limited number of preceptors. We assume that many preceptors teach students through case presentations as they have been taught. This study represents a first step towards investigating pharmacy preceptors' use of traditional methods as well as new methods from medical education to help ensure that precepting is evidence based. We adapted the OMP method, a method with some evidence for effectiveness, from medical education and applied it to the pharmacy setting. Overall, our results were mixed. We found that preceptors can employ the OMP to a purely therapeutic decision-making and reasoning process even though it was only previously applied to a diagnostic reasoning process. Now that we have developed a coding framework adapted for pharmacy education, future researchers may scale this study to a larger sample size. Some of our mixed findings may also be resolved with randomization and larger sample sizes. Alternatively, future researchers may adapt the OMP workshop or the OMP method itself to ensure that every pharmacy student commits to assessments and plans, explains their rationale, and receives needed feedback to promote optimal learning while caring for patients.

Our study has several limitations. First, our study was limited by a small sample size and analyzed at the level of observations. This study, ideally, would be conducted using a larger number of preceptors and students in the OMP and control group. As the data have a nested structure (ie, observations nested within students nested within preceptors), it would be ideal to use a multi-level model to analyze this data. ${ }^{27}$ However, we were unable to calculate a multilevel model because of the small sample size. Therefore, we were unable to calculate between-student and between-preceptor differences. Instead, we analyzed the data at the level of observations (ie, case presentations), testing for differences in code frequency and occurrence between the OMP group and control group. This inferential statistical analysis included a sample size of 17 in the control group and 25 in the OMP group. A second limitation of the study was the nonrandom sample that was used, ie, preceptors were assigned to the intervention or control group based on their geographical location. A third limitation of our study was that we only assessed students' therapeutic reasoning at one time point. Although this type of study is useful for exploring unreported student outcomes of preceptors attending an OMP workshop, a longitudinal study is needed to gain more insight into how the OneMinute Preceptor method develops students' therapeutic reasoning skills over time. Fourth, not unlike all observation studies, a limitation of this study was that preceptors 


\section{American Journal of Pharmaceutical Education 2019; 83 (8) Article 7212.}

and students may have behaved differently knowing they were being observed (ie, the Hawthorne effect). ${ }^{28}$ However, the Hawthorne effect was applicable to both groups and is known to fade over time. ${ }^{28}$

\section{CONCLUSION}

In conclusion, the use of the OMP as a model for precepting requires further consideration before implementing it widely for eliciting students' therapeutic reasoning in pharmacy education. Although the effects of an OMP workshop have been previously reported, ours is the first study, to our knowledge, to report student learning outcomes associated with the workshop and implement the OMP method in pharmacy. Future research is needed to ensure that preceptors' teaching behaviors foster students' therapeutic reasoning processes. How to achieve this is difficult to determine from this and other published studies as studies of fostering therapeutic reasoning are rare. Researchers must further study what expert preceptors do to foster therapeutic reasoning in a variety of contexts.

\section{REFERENCES}

1. Oderda GM, Zavod RM, Carter JT, et al. An environmental scan on the status of critical thinking and problem solving skills in colleges/schools of pharmacy: report of the 2009-2010 Academic Affairs Standing Committee. Am J Pharm Educ. 2010;74(10):Article S6.

2. Kielhofner G, Forsyth K. Therapeutic reasoning: planning, implementing and evaluating the outcomes of therapy. In: Kielhofner G, ed. Model of Human Occupation: Theory and Practice. Baltimore, MD: Lippincott Williams \& Wilkins; 2008:143-154.

3. Bissessur SW, Geijteman EC, Al Dulaimy M, et al. Therapeutic reasoning: from hiatus to hypothetical model. J Eval Clin Pract. 2009;15(6):985-989.

4. Ramani S, Leinster S. AMEE Guide no. 34: Teaching in the clinical environment. Med Teach. 2008;30(4):347-364.

5. Neher JO, Gordon KC, Meyer B, Stevens N. A five-step "microskills" model of clinical teaching. J Am Board Fam Pract. 1992;5(4):419-424.

6. Irby DM, Aagaard E, Teherani A. Teaching points identified by preceptors observing one-minute preceptor and traditional preceptor encounters. Acad Med. 2004;79(1):50-55.

7. Neher JO, Stevens NG. The one-minute preceptor: shaping the teaching conversation. Family Medicine-Kansas City.

2003;35(6):391-393.

8. Salerno SM, O'Malley PG, Pangaro LN, Wheeler GA, Moores LK, Jackson JL. Faculty development seminars based on the oneminute preceptor improve feedback in the ambulatory setting. $J$ Gen Intern Med. 2002;17(10):779-787.
9. Eckstrom E, Homer L, Bowen JL. Measuring outcomes of a oneminute preceptor faculty development workshop. J Gen Intern Med. 2006;21(5):410-414.

10. Aagaard E, Teherani A, Irby DM. Effectiveness of the oneminute preceptor model for diagnosing the patient and the learner: proof of concept. Acad Med. 2004;79(1):42-49.

11. Furney SL, Orsini AN, Orsetti KE, Stern DT, Gruppen LD, Irby DM. Teaching the one-minute preceptor. J Gen Intern Med. 2001;16(9):620-624.

12. Teherani A, O'Sullivan P, Aagaard EM, Morrison EH, Irby DM. Student perceptions of the one minute preceptor and traditional preceptor models. Med Teach. May 2007;29(4):323-327.

13. McBane SE, Dopp AL, Abe A, et al. Collaborative drug therapy management and comprehensive medication management - 2015 . ACCP White Paper. Pharmacother. 2015;35(4):e39-e50.

14. Kertis M. The one-minute preceptor: a five-step tool to improve clinical teaching skills. J Nurses Prof Dev. 2007;23(5):238-242.

15. Mededmmc. One minute preceptor. YouTube. https://youtu.be/ ndLbo7sDnKo. February 10, 2010. Accessed October 14, 2019.

16. Murnane RJ, Willett JB. Methods Matter: Improving Causal Inference in Educational and Ssocial Science Research. New York, NY: Oxford University Press; 2010:70.

17. Hsieh H-F, Shannon SE. Three approaches to qualitative content analysis. Qual Health Res. 2005;15(9):1277-1288.

18. Cohen J. A coefficient of agreement for nominal scales. Educ Psychol Meas. 1960;20(1):37-46.

19. Bernard HR, Wutich A, Ryan GW. Analyzing qualitative data: systematic approaches. Los Angeles, CA. Sage; 2017:256-261.

20. Kistner S, Rakoczy K, Otto B, Dignath-van Ewijk C, Büttner G, Klieme E. Promotion of self-regulated learning in classrooms: investigating frequency, quality, and consequences for student performance. Metacogn and Learn. 2010;5(2):157-171.

21. Donker A, de Boer H, Kostons D, van Ewijk CD, Van der Werf M. Effectiveness of learning strategy instruction on academic performance: a meta-analysis. Educ Res Rev. 2014;11:1-26.

22. Connell KJ, Bordage G, Chang RW, Howard BA, Sinacore J. Measuring the promotion of thinking during precepting encounters in outpatient settings. Acad Med. 1999;74(10):S10-S12.

23. Wolpaw T, Papp KK, Bordage G. Using SNAPPS to facilitate the expression of clinical reasoning and uncertainties: a randomized comparison group trial. Acad Med. 2009;84(4):517-524.

24. Landis JR, Koch GG. The measurement of observer agreement for categorical data. Biometrics. 1977:159-174.

25. Van de Pol J, Volman M, Beishuizen J. Scaffolding in teacherstudent interaction: a decade of research. Educ Psychol Rev.

2010;22(3):271-296.

26. Pascoe JM, Nixon J, Lang VJ. Maximizing teaching on the wards: review and application of the One-Minute Preceptor and SNAPPS models. J Hosp Med. 2015;10(2):125-130.

27. Heck RH, Thomas S, Tabata L. Multilevel modeling of categorical outcomes using IBM SPSS. 2nd ed. New York, NY. Routledge; 2013:1-9.

28. Jones SR. Was there a Hawthorne effect? Am J Sociol. 1992;98(3):451-456. 